\title{
The preventive effect of Nigella sativa seed on gastric ulcer induced by indomethacin in rat
}

\author{
Maryam Paseban $^{1,2}{ }^{\circledR}$, Saeed Niazmand ${ }^{1,3^{*}}{ }^{\circledR}$, Mohammad Soukhtanloo $^{4}$, Naser Tayyebi Meibodi ${ }^{\circledR}$ \\ ${ }^{1}$ Department of Physiology, School of Medicine, Mashhad University of Medical Sciences, Mashhad, Iran \\ ${ }^{2}$ Student Research Committee, Faculty of Medicine, Mashhad University of Medical Sciences, Mashhad, Iran \\ ${ }^{3}$ Neurogenic Inflammation Center, Mashhad University of Medical Sciences, Mashhad, Iran \\ ${ }^{4}$ Department of Biochemistry, School of Medicine, Mashhad University of Medical Sciences, Mashhad, Iran \\ ${ }^{5}$ Cutaneous Lishmanaisis Research Center, Faculty of Medicine, Mashhad University of Medical Sciences, Mashhad, Iran
}

\section{A R T I C L E I N F O}

Article Type:

Original Article

\section{Article History:}

Received: 18 September 2018

Accepted: 3 June 2019

\section{Keywords:}

Gastric ulcer

Indomethacin

Nigella sativa

Rat

Oxidative stress

\begin{abstract}
A B S T R A C T
Introduction: Nonsteroidal anti-inflammatory drugs (NSAIDs) are considered as one of the most administrated groups of medications worldwide. Due to the role of NSAIDs in inducing gastric ulceration, their clinical applications are still challenging. Nigella sativa seed is widely used as herbal medication against gastrointestinal complications. The present experiment was carried out to investigate the impact of $N$. sativa seed hydro-alcoholic extract on gastric ulcer induced by indomethacin (IND) and to evaluate its possible mechanisms in rat.

Methods: This study was performed on 48 male Wistar rats. Acute gastric ulceration was induced by IND $(35 \mathrm{mg} / \mathrm{kg})$. N. sativa seed extract $(100,200,400 \mathrm{mg} / \mathrm{kg})$ and ranitidine $(50$ $\mathrm{mg} / \mathrm{kg}$ ) were administered orally for five days before induction ulcer. Ulcer index, gastric acid secretion, gastric mucus content, glutathione (GSH), malondialdehyde (MDA), total hexose, gastric juice protein content were determined on the fifth day.

Results: The ulcer index in all groups of N. sativa seed was significantly lower than that of the IND group. $N$ sativa seed considerably decreased MDA and protein content, but increased total thiol, total hexose, and mucus content compared to the IND group. $N$. sativa seed did not affect gastric acid secretion.

Conclusion: These findings were indicative of the gastroprotective effect of $N$. sativa seed against the IND-induced ulcer, suggesting that it can mainly be exerted through the anti-oxidant activity of the extract as well as its role in stimulating gastric mucus secretion and increasing total hexose in the gastric mucosa.
\end{abstract}

Implication for health policy/practice/research/medical education:

This original research showed that Nigella sativa seed extracts protected the gastric mucosal layer against the gastric ulceration induced by indomethacin. Hence, it might be used with NSAIDs to protect gastrointestinal tract.

Please cite this paper as: Paseban M, Niazmand S, Soukhtanloo M, Tayyebi Meibodi N. The preventive effect of Nigella sativa seed on gastric ulcer induced by indomethacin in rat. J Herbmed Pharmacol. 2020;9(1):12-19. doi: 10.15171/jhp.2019.02.

\section{Introduction}

Nonsteroidal anti-inflammatory drugs (NSAIDs) are considered as one of the most usually administrated groups of medications worldwide. Due to the role of NSAIDs in inducing gastric ulceration, their application in clinical context has been limited $(1,2)$. Cyclooxygenase isoenzymes constantly produce prostaglandins that are essential for maintaining blood flow, producing mucus, and secreting bicarbonate in the gastric mucosa $(3,4)$.

The problematic properties of NSAIDs arise from their activity to inhibit cyclooxygenase crippling the gastric mucosa to withstand damage from exogenous and endogenous invaders.

Indomethacin (IND) is a medication of the NSAID family, which causes gastric ulceration through different mechanisms. This compound has been suggested to induce lipid peroxidation and apoptosis, infiltrate leukocytes, and inhibit prostaglandin synthesis resulting in the gastric lesion (5). Decrease in prostaglandin levels impairs almost all aspects of gastro-protection as well as acid secretion, 
which can aggravate the gastric ulcer. Additionally, IND is able to generate reactive oxygen species (ROS) (6), which can be strongly deleterious for the gastric mucosal defense. The production of ROS is well-documented to induce cell death (7) as well as microvascular injury (8), impairing gastric mucosal blood flow.

Nigella sativa is a herbal plant from the Ranunculaceae (buttercup) family known commonly as black cumin. The plant is native to Southwest Asia, North Africa, and Southern Europe. With focus on Middle East region, it grows in Turkey, Syria, Pakistan, Iran, Saudi Arabia, and India (9). In Folk (herbal) medicine, N. sativa seeds are usually utilized to treat or prevent numerous diseases such as diarrhea, asthma, and dyslipidemia (10). N. sativa is regarded as a common subject of study as believed to exert a therapeutic potential with a wide spectrum of properties including anti-inflammatory, (11) anti-oxidant (12), antibacterial (13), anti-diabetic, (14) hepato-protective, (13) and vaso-relaxant (15) effects. It has also been shown to reduce ischemia-reperfusion injury (13).

Polyphenols and tocopherols are the two compounds abundant in the seed oil of $N$. sativa (16). The seed has components such as essential (volatile oil, 0.4\%-2.5\%), fixed oils (28\%-36\%), saponins, proteins, and alkaloids. Palmitic (C16:0), oleic (C18:1), linoleic (C18:2), and stearic (C18:0) fatty acids are the main components of the fixed oil found in the seed (17).

From the pharmacological aspect, thymoquinone is the most active component found plentifully (30\% to $48 \%$ ) in the Nigella sativa seeds in addition to its derivatives such as thymol, thymohydroquinone, and dithymoquinone (17). Numerous animal experiments in which the gastric mucosal injury was induced by pyloric ligation (18), ethanol (19), ischemia-reperfusion (20), and stress (18) have been indicated that the acute usage of Nigella sativa oil and its integral ingredient thymoquinone exert gastroprotective properties.

The current experiment was designed to investigate the effect of pre-treatment with the hydro-alcoholic extract of Nigella sativa seed on IND-induced gastric ulcer.

\section{Materials and Methods}

Chemical substances

IND and ranitidine were purchased from Sigma (Germany).

All the chemical agents utilized for the histopathological and biochemical evaluations had analytical grade and were obtained from Merck Company (Germany).

\section{Extract preparation}

The $N$. sativa seed was bought from a vernacular herbal store in Mashhad, Iran. It was then identified by a botanist at Ferdowsi University Herbarium and deposited there a voucher specimen (voucher No. 176-2013-9). N. sativa seeds were powdered and drenched in ethanol 50\% at room temperature for 48 hours with occasional shaking.
The prepared solution was filtered and subjected to the vacuum full evaporation at $40^{\circ} \mathrm{C}$. The resulting extract then was saved at moisture-free $4^{\circ} \mathrm{C}$ and away from light. Afterward, it was added to distilled water in order to make the extract solutions of 100,200 , and $400 \mathrm{mg} / \mathrm{kg}$ body weight, which were selected according to our previous experiment (15).

Animals

This experiment was conducted on male Wistar rats with 3 months of age. The animals were housed in a standard status at $22 \pm 2^{\circ} \mathrm{C}$ with a 12-hour, light-dark cycle and free food/water availability. Prior to all assays, animals were fasted for 24 hours. Experimental groups consisted of 8 rats per group.

\section{Indomethacin-induced gastric ulcer}

During the fasting period, before IND administration, wide wire mesh-bottom cages were used to house the rats in order to avoid coprophagia. Ulceration was induced by IND oral administration (single dose, $35 \mathrm{mg} / \mathrm{kg}$ body weight) suspended in carboxymethyl cellulose $1 \%$.

\section{Experimental groups}

Animals were separated by random into 6 groups of 8 rats; control, IND, ranitidine, and three groups of Nigella sativa (Ns).

The control group was gavaged with normal saline for 4 days and IND vehicle (carboxymethyl cellulose 1\%) on the $5^{\text {th }}$ day; the IND group was gavaged with normal saline for 4 days and IND on the $5^{\text {th }}$ day to induce ulcer; the Ran group was gavaged with ranitidine $(50 \mathrm{mg} / \mathrm{kg}$ ) for 4 days and on the $5^{\text {th }}$ day, 2 hours before the IND administration; and the Ns groups (Ns 100, Ns 200, and Ns 400) was gavaged with the seed extract of Nigella sativa $(100,200$, and $400 \mathrm{mg} / \mathrm{kg}$ ) once a day for 4 days and on the $5^{\text {th }}$ day, 2 hours before the IND administration.

Collection of gastric juice and biochemical estimations One hour after the pyloric ligation, gastric juice was gathered and centrifuged at $3000 \mathrm{rpm}$ for 10 minutes. Then, the supernatant volume was titrated to $\mathrm{pH} 7.0$ using a 0.01 Molar $\mathrm{NaOH}$ solution and phenolphthalein reagent as indicator in order to determine the total gastric acid secretion. Later on, the protein content and total hexoses of the gastric juice were determined.

\section{Ulcer index}

In order to determine the ulcer index, a scoring method was employed according to Suzuki et al, in which the sum of the length $(\mathrm{mm})$ of all stomach lesions were measured (15). Then, the preventive percentage was determined using the formula below:

[(UI control - UI treated) / UI control] $\times 100$ 
Gastric mucus content determination

The mucous content of the gastric epithelial surface was measured in accordance with the method of Corne et al (21). After the removal of stomach glandular portion, it was buffered with sodium acetate $(50 \mathrm{mmol} / \mathrm{L}$ and $\mathrm{pH}$ $5.8)$ and plunged in $0.1 \%(\mathrm{w} / \mathrm{v})$ Alcian blue in sucrose $(160 \mathrm{mmol} / \mathrm{L})$. The unbound dye was diluted two times with sucrose $(250 \mathrm{mmol} / \mathrm{L})$ and the mucus-bound dye was extracted with $\mathrm{MgCl} 2$ (500 $\mathrm{mmol} / \mathrm{L}$ and $\mathrm{pH}$ 6). In the next step, an equal volume of diethyl ether was added to the solution, then centrifuged for 10 minutes at 3000 rpm. The Alcian blue content was then measured using spectrophotometry at $580 \mathrm{~nm}$.

\section{Total thiol measurement}

The gastric mucosal total thiol was determined in line with the method of Sedlak and Lindsay (22). According to this method, the glandular portions of treated and control animals were separated, homogenized in ice-cold, and centrifuged. The resulting supernatant $(50 \mu \mathrm{L})$ was added to $1 \mathrm{ml}$ of Tris-EDTA buffer with the $\mathrm{pH}$ of 8.6 and the absorbance was read at the wavelength of $412 \mathrm{~nm}$ against the Tris-EDTA buffer alone (A1). Afterward, 20 $\mu \mathrm{L}$ of DTNB (10 mM in methanol) was mixed with the supernatant and the absorbance was read for the second time (A2). The absorbance of DTNB was also read as blank (B). The total thiol content was expressed as $\mathrm{mmol} / \mathrm{g}$ tissue.

\section{Measurement of MDA}

The MDA level was measured using thiobarbituric acid (TBA) as described by Mihara et al (23). One milliliter of the supernatant obtained from the homogenized glandular portion of stomachs was added to $2 \mathrm{ml}$ of a complex solution having trichloroacetic acid (TCA), $\mathrm{HCl}$, and TBA. It was then placed in a boiling water bath for 40 minutes. When reached the room temperature, it was centrifuged at $1000 \mathrm{~g}$ for 10 minutes. The absorbance was read at the wavelength of $535 \mathrm{~nm}$. The level of MDA was represented as $\mu \mathrm{mol} / \mathrm{g}$ tissue.

Measurement of total hexoses and protein

The measurement of total hexoses in gastric juice was according to Anthrone's method using glucose as the standard $(24,25)$. The reaction mixture contained 0.05 $\mathrm{mL}$ of the supernatant of gastric juice, $0.05 \mathrm{~mL}$ of distilled water, and $0.4 \mathrm{~mL}$ of Anthrone reagent, which was placed in a boiling water bath for 10 minutes. Then, the absorbance was read at the wavelength of $490 \mathrm{~nm}$.

The protein content of gastric juice was evaluated in line with the Bradford method (26). Briefly, $100 \mu \mathrm{L}$ of the gastric juice was added to $5 \mathrm{~mL}$ Bradford reagent, then the absorbance was read at the wavelength of $595 \mathrm{~nm}$. Different concentrations (100-1000 $\mu \mathrm{g})$ of bovine serum albumin (BSA) were used as standard.
Histopathological procedures and evaluation

As for histopathological evaluation, the formaldehyde solution (10\%) was used in order to fix the samples and embed them in paraffin. A microtome was used to slice the tissue in a longitudinal axis into $5 \mathrm{~mm}$ thick segments. Each segment was stained with hematoxylin-eosin to evaluate the gastric morphology. The tissue damage was scored as follows: score 0: no lesions; 1: diffuse hyperaemia; 2: one or two hemorrhagic erosions or lesions; 3: three to five hemorrhagic lesions or erosions; 4: more than 5 hemorrhagic erosions or lesions; 5: 20 to $40 \%$ of total gastric mucosal layer with hemorrhagic lesions or multiple erosions; and 6: higher than $40 \%$ of total gastric mucosal layer with hemorrhagic lesions or multiple erosions. Polymorpho-nuclear leukocytes (PMNs) were counted in 20 microscopic fields $(\times 250)$ (27).

Data statistical analysis

The data were represented as mean \pm standard error of mean (SEM). In order for the statistical analysis, the oneway ANOVA procedure was performed and followed by Tukey post hoc test. $P$ values $\leq 0.05$ were regarded as significant.

\section{Results}

The effect of Nigella sativa seed on gastric ulcer and acid secretion

As Figure 1 depicts, ranitidine and N. sativa seed extracts ameliorated the IND injurious effects. Ranitidine showed a preventative index of $64.6 \%$, while $N$. sativa seed extract revealed $76.1 \%$ for $100 \mathrm{mg} / \mathrm{kg}, 88.4 \%$ for $200 \mathrm{mg} / \mathrm{kg}$, and $52.1 \%$ for $400 \mathrm{mg} / \mathrm{kg}$ body weight. Although the basal gastric acid secretion was not significantly influenced by $N$. sativa seed extracts (Figure 2).

The effect of Nigella sativa seed on gastric mucus content As demonstrated in Figure 3, pre-treatment with ranitidine caused an increase of $35.6 \%$, while the administration of $N$. sativa extracts respectively resulted in a $164.5 \%$ increase

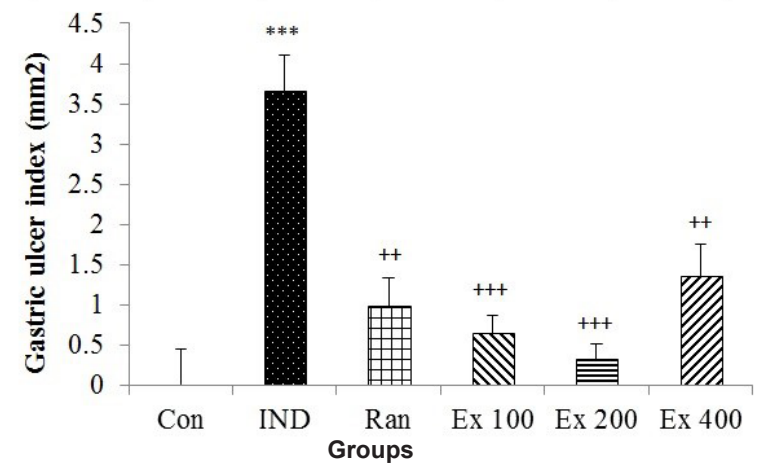

Figure 1. Effect of $N$. sativa seed on gastric ulcer index in indomethacininduced gastric ulcer. Con: control group, IND: indomethacin group, Ran: ranitidine group, Ex: Nigella sativa seed groups. Values are expressed as mean \pm SEM, $(n=8),{ }^{* * *} P<0.001$ versus control group, $+++P<0.001$ versus indomethacin group. 


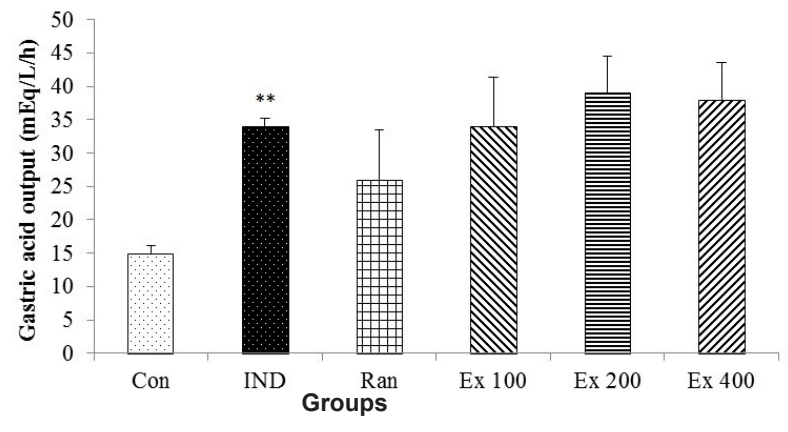

Figure 2 Effect of $N$. sativa seed on gastric acid output in indomethacininduced gastric ulcer. Con: control group, IND: indomethacin group, Ran: ranitidine group, Ex: Nigella sativa seed groups. Values are expressed as mean \pm SEM, $(n=8),{ }^{* *} P<0.01$ versus control group.

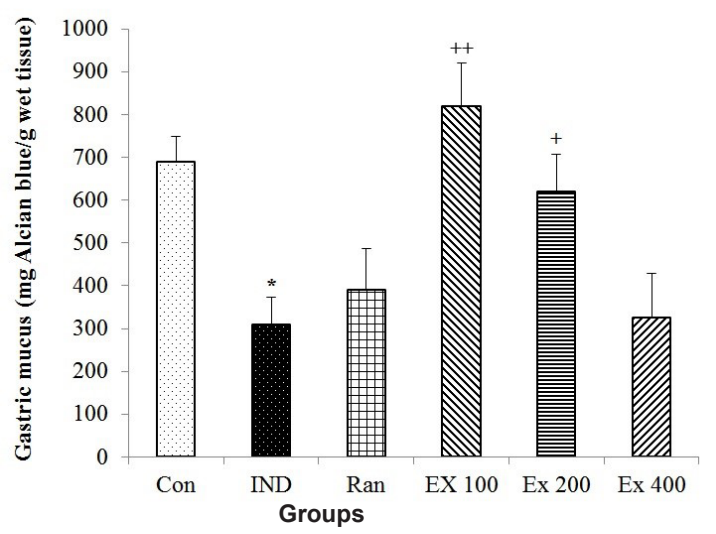

Figure 3. Effect of $\mathrm{N}$. sativa seed on gastric mucus secretion in indomethacin-induced gastric ulcer. Con: control group, IND: indomethacin group, Ran: ranitidine group, Ex: Nigella sativa seed groups. Values are expressed as mean \pm SEM, $(n=8),{ }^{*} P<0.05$ versus control group, $+P<0.05,++P<0.05$ versus indomethacin group.

per $100 \mathrm{mg} / \mathrm{kg}$ body weight, a 100\% increase per $200 \mathrm{mg} /$ $\mathrm{kg}$ body weight, and a $37.1 \%$ increase per $400 \mathrm{mg} / \mathrm{kg}$ body weight in gastric mucus content compared to IND.

The effect of Nigella sativa seed on total thiol content As revealed in Figure 4, the total thiol concentration of the gastric tissue increased by $17.3 \%$ in the ranitidine group, while in the $N$. sativa groups, total thiol concentration increased by $27.7 \%, 16.6 \%$, and $17.8 \%$ per $100 \mathrm{mg} / \mathrm{kg}$, $200 \mathrm{mg} / \mathrm{kg}$, and $400 \mathrm{mg} / \mathrm{kg}$ body weight, respectively, in comparison to IND. However, total thiol concentration differences among the groups were insignificant.

The effect of Nigella sativa seed on MDA level

As indicated in Figure 5, pre-treatment with ranitidine decreased the MDA level by $56.3 \%$, while pre-treatment with $N$. sativa extracts decreased the MDA levels respectively $82.5 \%, 82.7 \%$, and $77 \%$ per $100 \mathrm{mg} / \mathrm{kg}, 200$ $\mathrm{mg} / \mathrm{kg}$, and $400 \mathrm{mg} / \mathrm{kg}$ body weight compared to IND.

The effect of Nigella sativa seed on total hexose As shown in Figure 6, the amount of total hexose

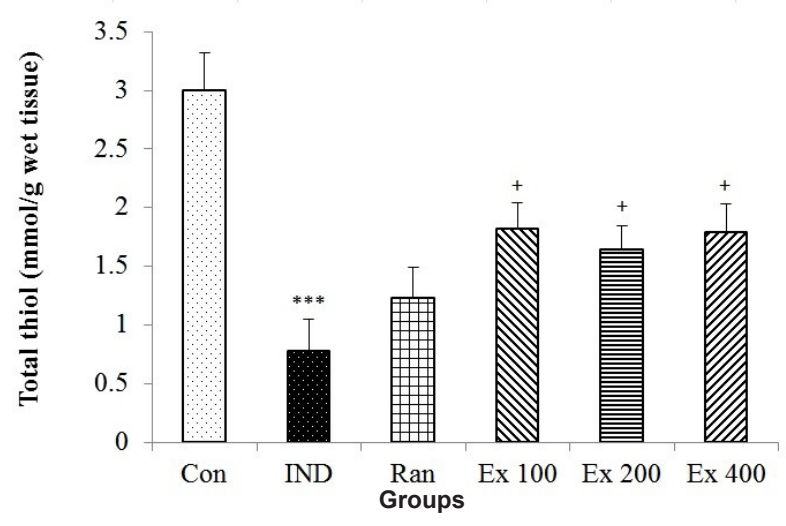

Figure 4. Effect of $\mathrm{N}$. sativa seed on total thiol concentration in indomethacin-induced gastric ulcer. Con: control group, IND: indomethacin group, Ran: ranitidine group, Ex: Nigella sativa seed groups. Values are expressed as mean \pm SEM, $(n=8)$, ${ }^{* * *} P<0.001$ versus control group, $+P<0.05$ versus indomethacin group.

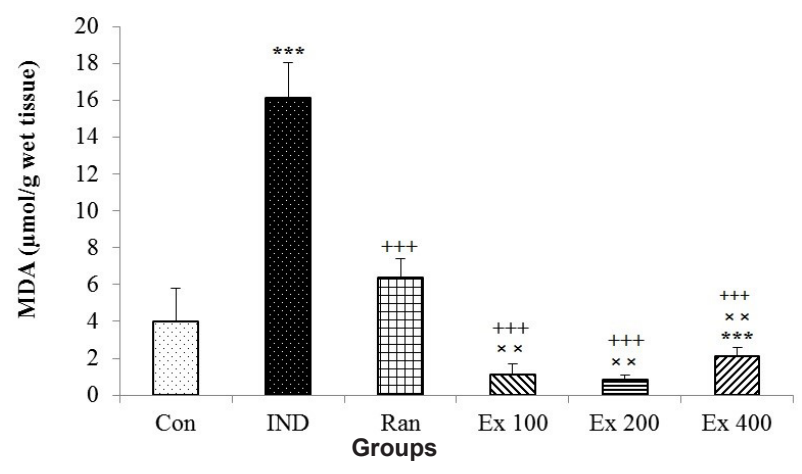

Figure 5. Effect of N. sativa seed on MDA concentration in indomethacininduced gastric ulcer. Con: control group, IND: indomethacin group, Ran: ranitidine group, Ex: Nigella sativa seed groups. Values are expressed as mean \pm SEM, $(\mathrm{n}=8),{ }^{* * *} P<0.001$ versus control group, $+++P<0.001$ versus indomethacin group, ${ }^{\times x} P<0.01$ versus ranitidine group.

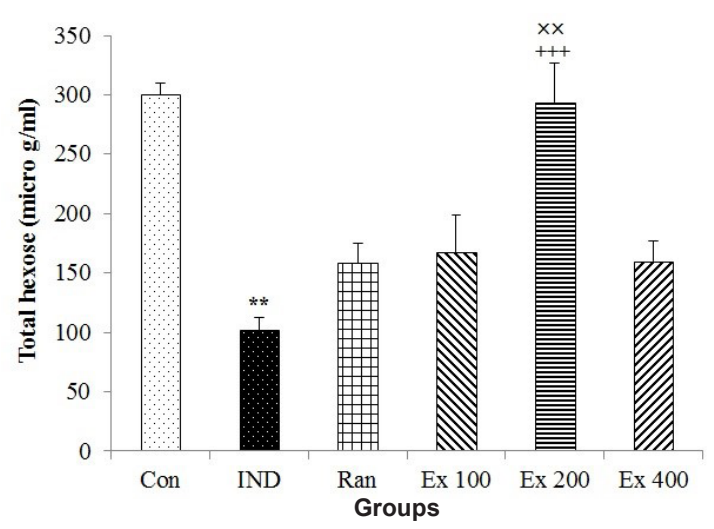

Figure 6. Effect of $\mathrm{N}$. sativa seed on total hexose content in indomethacininduced gastric ulcer. Con: control group, IND: indomethacin group, Ran: ranitidine group, Ex: Nigella sativa seed groups. Values are expressed as mean \pm SEM, $(n=8)$, ${ }^{* *} P<0.01$ versus control group, $+++P<0.001$ versus indomethacin group, ${ }^{\times x} P<0.01$ versus ranitidine group.

considerably increased in the ranitidine group (55\%). On the other hand, following the administration of $N$. sativa seed extract, an increase of respectively $67 \%, 189 \%$, and $60 \%$ in total hexose was observed per 100,200 , and 400 
$\mathrm{mg} / \mathrm{kg}$ body weight, relative to IND.

The effect of Nigella sativa seed on the protein content of the gastric juice

As demonstrated in Figure 7, Pre-treatment with ranitidine decreased the protein content by $8 \%$, while the $N$. sativa seed extracts decreased the protein content by $30 \%, 5 \%$, and $23 \%$ per 100,200 , and $400 \mathrm{mg} / \mathrm{kg}$ body weight, respectively, in comparison to IND.

The effect of Nigella sativa seed on carbohydrate to protein ratio

As indicated in Figure 8, pre-treatment with ranitidine increased the carbohydrate to protein ratio by $69 \%$, while the seed extracts of $N$. sativa increased the ratio respectively by $136 \%, 209 \%$, and $100 \%$ per $100 \mathrm{mg} / \mathrm{kg}, 200$ $\mathrm{mg} / \mathrm{kg}$, and $400 \mathrm{mg} / \mathrm{kg}$ body weight in comparison to IND.

Histopathological results

The results of histopathology were indicative of an intense IND-induced mucosal and submucosal injury followed

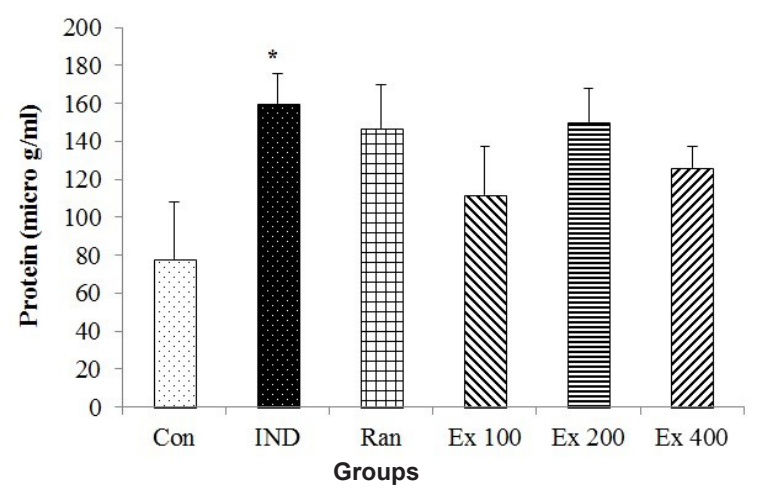

Figure 7. Effect of N. sativa seed on protein content in indomethacininduced gastric ulcer. Con: control group, IND: indomethacin group, Ran: ranitidine group, Ex: Nigella sativa seed groups. Values are expressed as mean \pm SEM, $(n=8),{ }^{*} P<0.05$ versus control group.

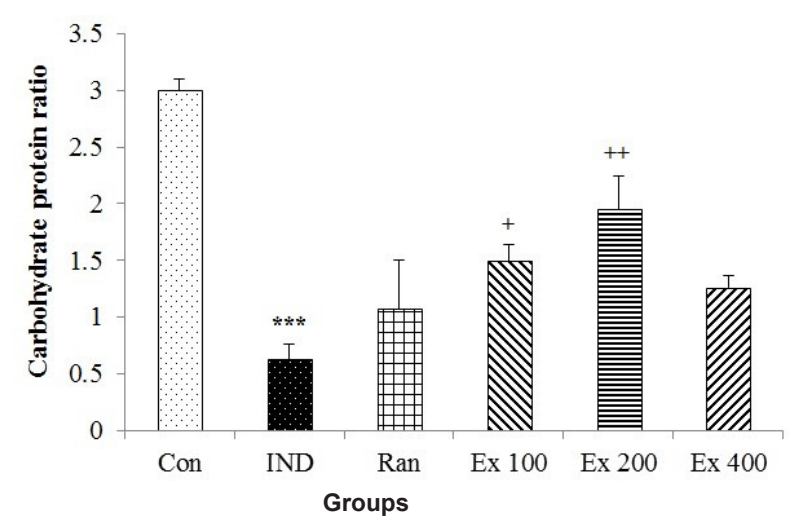

Figure 8. Effect of $\mathrm{N}$. sativa seed on carbohydrate protein ratio in indomethacin-induced gastric ulcer. Con: control group, IND: indomethacin group, Ran: ranitidine group, Ex: Nigella sativa seed groups. Values are expressed as mean \pm SEM, $(n=8)$, ${ }^{* * *} P<0.001$ versus control group, $+P<0.05$ versus indomethacin group. by impaired tissue integrity, hyperemia, hemorrhagic lesions, erosions, and infiltration of PMNs to mucosa and submucosa. The extent of tissue damage was less in ranitidine group. It was observed that the hemorrhagic lesions, erosions, and infiltration of PMNs were significantly lower in the groups treated with $N$. sativa seed compared to IND (Figure 9).

\section{Discussion}

The present study was carried out in order to investigate the gastroprotective impacts of the $N$. sativa seed on INDinduced gastric ulcers. Ulcer and preventive indices are representative of the protective properties of $N$. sativa.

Use of NSAIDs in clinical settings has been hindered due to their toxic gastrointestinal effects (28). According to the literature, it is widely accepted that the ulcerogenic impact of the NSAIDs is associated with their activity to inhibit the synthesis of endogenous prostaglandins through the inhibition of cyclooxygenase (29). Prostaglandins are considered as one of the most essential components in the gastric mucosal defense. These compounds are generated in a high concentration and taken into account as to improve the mucosal blood flow as well as to stimulate the glutathione $(\mathrm{GSH})$ production and mucus/bicarbonate secretion. They also can influence gastric acid production (30).

In the present study, the chronic pre-treatment with $N$. sativa seed extract led to a significant increase in total hexose and mucus levels as shown in Figure 6. The elevated hexose and mucus may increase the viscosity of gastric mucus (31) and consequently promote the efficacy of gastric mucosal barrier as a potential mechanism explaining its anti-ulcerogenic and cytoprotective properties. Decline in gastric juice proteins is an indicative of insufficient secretion by mucosal cells exerted as elevated mucosal resistance (32). Additionally, the elevated total carbohydrates: protein (TC: $\mathrm{P}$ ) ratio is considered as a valid index of mucin secretion (32).

Aside from the impairment in prostaglandin production, which is due to the cyclooxygenase inhibition, NSAIDs can also induce mucosal layer damage through the ROS generated by the leukocytes recruited to the lesion site. ROS-dependent DNA, protein, and lipid oxidation together with the mitochondrial damage can result in the mucosal injury and apoptosis. Malondialdehyde, as a product of lipid peroxidation, has a cytotoxic effect and alters cell membrane function and structure (33). ROS molecules can also exasperate gastrointestinal ulcers. The gastric mucosal epithelium has been found to be the main target for free radicals generated in the lumen. Antioxidant compounds, which have the reducing property, demonstrate their effect by donating a hydrogen atom to the ferric complex and consequently blocking the radical chain reaction (34).

Thiol groups are endogenous anti-oxidants that play 


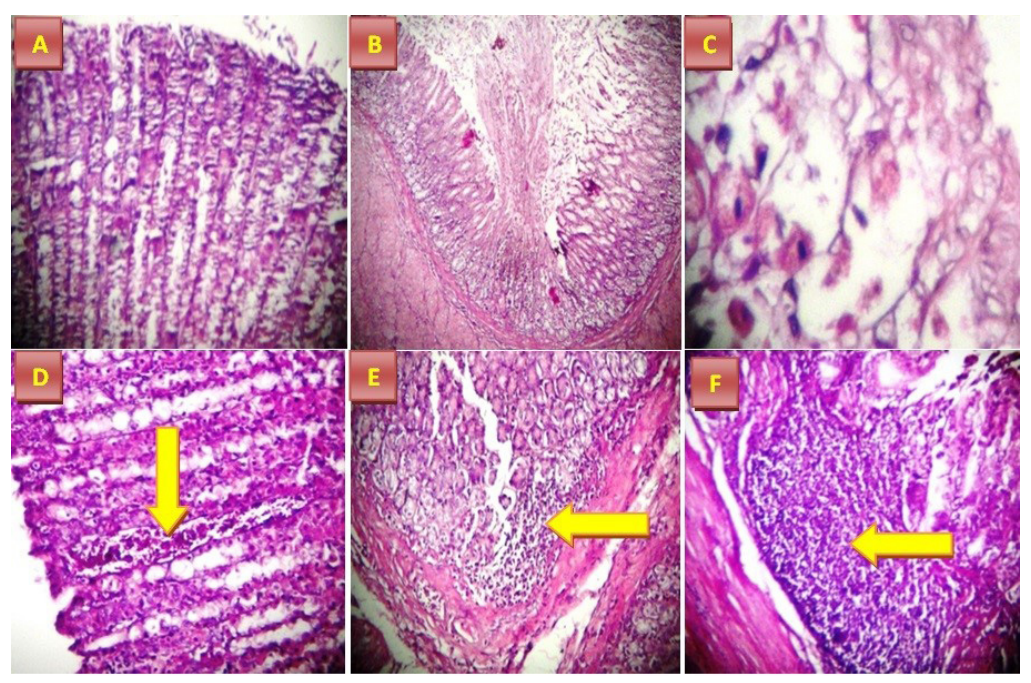

Figure 9. A: Normal gastric mucosa tissue sections were photographed at a $\times 10$ magnification. B: Focal necrosis in the gastric mucosa surface (original magnification, $\times 10$ ). C: Focal necrosis in the gastric mucosa surface (original magnification, $\times 40$ ). D: Vascular congestion of gastric mucosa (original magnification, $\times 10$ ). E: Lymphoid accumulation in the gastric mucosa (original magnification, $\times 10$. F: Lymphoid accumulation in the gastric sub mucosa (original magnification, $\times 10$ ). Arrows in Figures $\mathrm{D}, \mathrm{E}$, and $\mathrm{F}$ stand for vascular congestion of gastric mucosa, Lymphoid accumulation in the gastric mucosa and lymphoid accumulation in the gastric sub mucosa, respectively.

a significant role in protecting the gastric mucosal layer against destructive molecules (35). According to investigations, different ulcerogenic molecules have been found which can induce tissue injury by declining the endogenous levels of total thiol content (36). Additionally, thiol groups control mucus production to protect the mucosal epithelium against ROS-mediated gastric damages (37).

The present study revealed that IND administration induced mucosal damage, which was in association with a meaningful elevation in MDA concentration and a considerable drop in total thiol level. The chronic pretreatment with the seed extract of $N$. sativa reduced MDA level and increased the amount of total thiol. These findings indicated that the $N$. sativa seed exerts a gastroprotective effect through the anti-oxidation mechanism.

Kanter et al. showed that $N$. sativa seed oil $(10 \mathrm{~mL} /$ $\mathrm{kg}$ body weight orally, 1 hour prior to ethanol intake) protected the gastric mucosal layer against the deleterious impact of absolute alcohol, and attenuated the ulcer mainly by improving the oxidative status (19). In another study, it was reported that the seed extract of $N$. sativa (500 $\mathrm{mg} / \mathrm{kg}$ body weight) and its constituent, thymoquinone (TQ, $10 \mathrm{mg} / \mathrm{kg}$, which was administered 1 hour before the ethanol-induced gastric mucosal damage) were able to protect the gastric layer against mucosal damage. This gastroprotective activity is more likely to be as a result of the anti-histaminic, anti-oxidant, and anti-peroxidative effects of $N$. sativa and thymoquinone (38). Furthermore, Abdel-Sater et al. have revealed that the $N$. sativa seed oil can influence stress-induced gastritis in hypo-thyroidal rats via its gastroprotective aspects. He also demonstrated that $N$. sativa seed oil decreased the gastric MDA (39). In addition, $N$. sativa seed increased the GSH level of gastric mucosa (38). This investigation also indicated that $N$. sativa seed increased total thiol content in gastric mucosa.

Gastric mucus activity has been found to be a vitally protective mechanism in physiological conditions, maintaining the integrity of the epithelial layer. IND inhibits mucus secretion by blocking the biosynthesis of prostaglandins (40). There are several mechanisms through which mucosal secretion can promote the hydrochloric acid buffering in gastric juice and reduce wall friction during gastric contractions and peristalsis. Also, mucus secretion is a beneficial barrier to $\mathrm{H}^{+}$back diffusion (41).

In the current study, following the administration of IND, the gastric mucus content decreased significantly, while in extract-treated groups, the gastric mucus content considerably increased. These findings suggest that the possible mechanism of the gastroprotective effect of $N$. sativa can be related to the factors regulating gastric mucus. The previous study has shown that the N. sativa aqueous suspension increased gastric mucus content in acute ethanol-induced gastric ulcer (42).

The histopathological results of this study indicated that treatment with IND caused gastric mucosal hemorrhagic damages. The results also showed that the animals treated with $N$. sativa had a significant amelioration of hemorrhagic and erosional damages. According to these findings, it was well-confirmed that the seed extract of $N$. sativa attenuated ulcer index and showed a preventive property against IND-induced gastric ulcers.

In agreement with our findings, previous studies have shown that some chemical components of $N$. sativa seed exert gastroprotective effects. Rocha et al observed that 
the cineole extract led to a gastroprotection in acute ulceration induced by ethanol and IND through an antioxidation mechanism (43). In addition, Bonamin et al revealed the gastroprotective impact of $\beta$-myrcene in experimental models of ulcers (44).

\section{Conclusion}

With regard to the findings of this investigation, it was demonstrated that Nigella sativa seed extracts protected the gastric mucosal layer against the gastric ulceration induced by IND. The gastroprotective effect of $N$. sativa seed sounds to be mediated through a direct anti-oxidant activity as well as an indirect role in gastric mucus secretion and TC: $\mathrm{P}$ ratio elevation. The results of this investigation are indicative of the ethnomedicinal application of $N$. sativa seed in preventing or treating gastric disorders.

\section{Acknowledgments}

The authors would like to thank the Research Affairs of Mashhad University of Medical Sciences for their financial support.

\section{Authors' contributions}

All the authors contributed to data collection and preparation of the manuscript. The first draft was prepared by SN and MP. All authors read the final version and confirmed for the publication

\section{Conflict of interests}

The authors declare no conflict of interest regarding the publication of this paper.

\section{Ethical considerations}

Ethical issues have been observed by the authors. All the procedures were approved by the Ethical Committee of Mashhad University of Medical Sciences (Approval No. 89529)

\section{Funding/Support}

This research was financially supported by Mashhad University of Medical Sciences Grants Commission (UGC) (Grant No. 89529).

\section{References}

1. Hawkey CJ, Langman MJ. Non-steroidal anti-inflammatory drugs: overall risks and management. Complementary roles for COX-2 inhibitors and proton pump inhibitors. Gut. 2003;52(4):600-8. doi: 10.1136/gut.52.4.600.

2. Hawkins C, Hanks GW. The gastroduodenal toxicity of nonsteroidal anti-inflammatory drugs: a review of the literature. J Pain Symptom Manage. 2000;20(2):140-51.

3. Wallace JL, McKnight W, Reuter BK, Vergnolle N. NSAIDinduced gastric damage in rats: requirement for inhibition of both cyclooxygenase 1 and 2. Gastroenterology. 2000;119(3):706-14. doi: 10.1053/gast.2000.16510.

4. Ishihara K, Kuwata H, Ohara S, Okabe H, Hotta K. Changes of rat gastric mucus glycoproteins in cytoprotection: influences of prostaglandin derivatives. Digestion. 1988;39(3):162-71. doi: 10.1159/000199621.

5. Beck PL, Xavier R, Lu N, Nanda NN, Dinauer M, Podolsky DK, et al. Mechanisms of NSAID-induced gastrointestinal injury defined using mutant mice. Gastroenterology. 2000;119(3):699-705. doi: 10.1053/gast.2000.16497.

6. Ohkuma T, Utsumi N, Tsutsumi K, Murata K, Sandoval C, Noyori R. The hydrogenation/transfer hydrogenation network: asymmetric hydrogenation of ketones with chiral eta6-arene/N-Tosylethylenediamine-ruthenium (II) catalysts. J Am Chem Soc. 2006;128(27):8724-5. doi: 10.1021/ja0620989.

7. Kusuhara H, Komatsu H, Sumichika H, Sugahara K. Reactive oxygen species are involved in the apoptosis induced by nonsteroidal anti-inflammatory drugs in cultured gastric cells. Eur J Pharmacol. 1999;383(3):331-7. doi: 10.1016/s0014-2999(99)00599-3.

8. Naito Y, Yoshikawa T. Oxidative stress involvement and gene expression in indomethacin-induced gastropathy. Redox Rep. 2006;11(6):243-53. doi: 10.1179/135100006x155021.

9. Ahmad A, Husain A, Mujeeb M, Khan SA, Najmi AK, Siddique NA, et al. A review on therapeutic potential of Nigella sativa: A miracle herb. Asian Pac J Trop Biomed. 2013;3(5):337-52. doi: 10.1016/s2221-1691(13)60075-1.

10. Sharif Moghaddasi M. Nigella sativa traditional usages (Black seed). Adv Environ Biol. 2011;5(1):5-16.

11. Aydin MS, Kocarslan A, Kocarslan S, Kucuk A, Eser I, Sezen $\mathrm{H}$, et al. Thymoquinone protects end organs from abdominal aorta ischemia/reperfusion injury in a rat model. Rev Bras Cir Cardiovasc. 2015;30(1):77-83. doi: 10.5935/1678-9741.20140066.

12. Mosbah A, Sobhi W, Benboubetra M. Antioxidant and anti-hemolitic activities of Algerian Nigella sativa total oil and its neutral lipid fraction. Int J Pharm Pharm Sci. 2015;7(11):50-4.

13. Rahmani AH, Aly SM. Nigella sativa and its active constituents thymoquinone shows pivotal role in the diseases prevention and treatment. Asian J Pharm Clin Res. 2015;8(1):48-53.

14. Adnyana IK, Sigit JI, Asad SA. Antidiabetic activity of Nigella sativa L. seed powder and its combination with gliclazide in alloxan induced diabetic mice. Int J Pharm Pharm Sci. 2014;6(10):434-7.

15. Abbasnezhad A, Niazmand S, Mahmoudabady M, Soukhtanloo M, Rezaee SA, Mousavi SM. Nigella sativa seed decreases endothelial dysfunction in streptozotocininduced diabetic rat aorta. Avicenna J Phytomed. 2016;6(1):67-76.

16. Suzuki Y, Ishihara M, Segami T, Ito M. Anti-ulcer effects of antioxidants, quercetin, alpha-tocopherol, nifedipine and tetracycline in rats. Jpn J Pharmacol. 1998;78(4):435-41. doi: $10.1254 /$ jjp.78.435.

17. Nickavar B, Mojab F, Javidnia K, Amoli MA. Chemical composition of the fixed and volatile oils of Nigella sativa $\mathrm{L}$. from Iran. Z Naturforsch C. 2003;58(9-10):629-31.

18. uz Zaman R, Akhtar MS, Khan MS. Anti-ulcer activity of NS-EA 51-A fraction of Nigella sativa seed, in histamine plus pylorus-ligated and hypothermia plus restrain stressed rat models. J Pharm Res. 2013;6(1):16-20. doi: 10.1016/j. 
jopr.2012.11.007

19. Kanter M, Demir H, Karakaya C, Ozbek H. Gastroprotective activity of Nigella sativa $\mathrm{L}$ oil and its constituent, thymoquinone against acute alcohol-induced gastric mucosal injury in rats. World J Gastroenterol. 2005;11(42):6662-6. doi: 10.3748/wjg.v11.i42.6662.

20. Tas U, Ayan M, Sogut E, Kuloglu T, Uysal M, Tanriverdi $\mathrm{HI}$, et al. Protective effects of thymoquinone and melatonin on intestinal ischemia-reperfusion injury. Saudi J Gastroenterol. 2015;21(5):284-9. doi: 10.4103/13193767.166203

21. Corne SJ, Morrissey SM, Woods RJ. Proceedings: A method for the quantitative estimation of gastric barrier mucus. J Physiol. 1974;242(2):116p-7p.

22. Sedlak J, Lindsay RH. Estimation of total, proteinbound, and nonprotein sulfhydryl groups in tissue with Ellman's reagent. Anal Biochem. 1968;25(1):192-205. doi: 10.1016/0003-2697(68)90092-4.

23. Mihara M, Uchiyama M. Determination of malonaldehyde precursor in tissues by thiobarbituric acid test. Anal Biochem. 1978;86(1):271-8. doi: 10.1016/00032697(78)90342-1.

24. Loewus FA. Improvement in anthrone method for determination of carbohydrates. Anal Chem. 1952;24(1):219. doi: 10.1021/ac60061a050.

25. Yasar S. Spectrophotometric determination of hexose and pentose amounts by artificial neural network calibration and its using in wood analysis. Acta Chim Slov. 2005;52(4):435-9.

26. Lowry OH, Rosebrough NJ, Farr AL, Randall RJ. Protein measurement with the Folin phenol reagent. J Biol Chem. 1951;193(1):265-75.

27. Melchiorri D, Sewerynek E, Reiter RJ, Ortiz GG, Poeggeler B, Nistico G. Suppressive effect of melatonin administration on ethanol-induced gastroduodenal injury in rats in vivo. Br J Pharmacol. 1997;121(2):264-70. doi: 10.1038/ sj.bjp.0701104.

28. Mandegaran R, Conway C, Elton C. Lower gastrointestinal adverse effects of NSAIDS: an extreme example of a common problem. BMJ Case Rep. 2013;2013. doi: 10.1136/ bcr-2012-008274.

29. Wallace JL, Vong L. NSAID-induced gastrointestinal damage and the design of GI-sparing NSAIDs. Curr Opin Investig Drugs. 2008;9(11):1151-6.

30. Tarnawski AS, Ahluwalia A, Jones MK. The mechanisms of gastric mucosal injury: focus on microvascular endothelium as a key target. Curr Med Chem. 2012;19(1):4-15.

31. Rao CV, Sairam K, Goel RK. Experimental evaluation of Bocopa monniera on rat gastric ulceration and secretion. Indian J Physiol Pharmacol. 2000;44(4):435-41.

32. Menguy R, Desbaillets L. The gastric mucous barrier: influence of protein-bound carbohydrate in mucus on the rate of proteolysis of gastric mucus. Ann Surg. 1968;168(3):475-82. doi: 10.1097/00000658-19680900000014 .
33. Takeuchi K, Ueshima K, Hironaka Y, Fujioka Y, Matsumoto J, Okabe S. Oxygen free radicals and lipid peroxidation in the pathogenesis of gastric mucosal lesions induced by indomethacin in rats. Relation to gastric hypermotility. Digestion. 1991;49(3):175-84. doi: 10.1159/000200718.

34. Shakirin FH, Prasad KN, Ismail A, Yuon LC, Azlan A. Antioxidant capacity of underutilized Malaysian Canarium odontophyllum (dabai) Miq. fruit. J Food Compost Anal. 2010;23(8):777-81. doi: 10.1016/j.jfca.2010.04.008.

35. Szabo S, Trier JS, Frankel PW. Sulfhydryl compounds may mediate gastric cytoprotection. Science. 1981;214(4517):200-2. doi: 10.1126/science.7280691.

36. Rafatullah S, Galal AM, Al-Yahya MA, Al-Said MS. Gastric and duodenal antiulcer and cytoprotective effects of Aframomum melegueta in rats. Int J Pharmacogn. 1995;33(4):311-6. doi: 10.3109/13880209509065384.

37. Andreo MA, Ballesteros KV, Hiruma-Lima CA, Machado da Rocha LR, Souza Brito AR, Vilegas W. Effect of Mouriri pusa extracts on experimentally induced gastric lesions in rodents: role of endogenous sulfhydryls compounds and nitric oxide in gastroprotection. J Ethnopharmacol. 2006;107(3):431-41. doi: 10.1016/j.jep.2006.04.001.

38. Kanter $\mathrm{M}$, Coskun $\mathrm{O}$, Uysal $\mathrm{H}$. The antioxidative and antihistaminic effect of Nigella sativa and its major constituent, thymoquinone on ethanol-induced gastric mucosal damage. Arch Toxicol. 2006;80(4):217-24. doi: 10.1007/s00204-005-0037-1.

39. Abdel-Sater KA. Gastroprotective effects of Nigella sativa oil on the formation of stress gastritis in hypothyroidal rats. Int J Physiol Pathophysiol Pharmacol. 2009;1(2):143-9.

40. Bandyopadhyay SK, Pakrashi SC, Pakrashi A. The role of antioxidant activity of Phyllanthus emblica fruits on prevention from indomethacin induced gastric ulcer. J Ethnopharmacol. 2000;70(2):171-6.

41. Khushtar M, Kumar V, Javed K, Bhandari U. Protective effect of ginger oil on aspirin and pylorus ligation-induced gastric ulcer model in rats. Indian J Pharm Sci. 2009;71(5):554-8. doi: 10.4103/0250-474x.58195.

42. Al Mofleh IA, Alhaider AA, Mossa JS, Al-Sohaibani MO, Al-Yahya MA, Rafatullah S, et al. Gastroprotective effect of an aqueous suspension of black cumin Nigella sativa on necrotizing agents-induced gastric injury in experimental animals. Saudi J Gastroenterol. 2008;14(3):128-34. doi: 10.4103/1319-3767.41731.

43. Rocha Caldas GF, da Silva Oliveira AR, Araújo AV, Lafayette SS, Albuquerque GS, da Costa Silva-Neto J, et al. Gastroprotective Mechanisms of the Monoterpene 1,8-Cineole (Eucalyptol). PLoS One. 2015;10(8):e0134558. doi: $\quad$ 10.1371/journal.pone.0134558.

44. Bonamin F, Moraes TM, Dos Santos RC, Kushima H, Faria FM, Silva MA, et al. The effect of a minor constituent of essential oil from Citrus aurantium: the role of betamyrcene in preventing peptic ulcer disease. Chem Biol Interact. 2014;212:11-9. doi: 10.1016/j.cbi.2014.01.009. 